Jurnal Informatika dan Rekayasa Perangkat Lunak (JATIKA)
Vol. 2, No.3, September 2021, page-page. 361 367
ISSN 2723-3367
E-ISSN 2797-3492
available online at:http://jim.teknokrat.ac.id/index.php/informatika

\title{
PERANCANGAN APLIKASI E-MARKETING MENGGUNAKAN RESPONSIVE WEB DESIGN
}

\author{
Rio Agustian \\ Universitas Teknokrat Indonesia \\ rio_agustian@teknokrat.ac.id
}

Published: 30 September 2021

\begin{abstract}
E-marketing is part of e-commerce which is a trading system through the internet, where the internet will continue to provide an up to date nature, so the company can provide product information services offered clearly and easily. This will have a good impact on the progress of the company if this system can be run properly. E-marketing is widely done to improve the company's brand image because it makes the company always remembered by its customers. E-marketing provides more convenience and benefits for the company, customers and business partners of the company. Seeing marketing media that are still conventional, it is built online responsive web design applications as a support for marketing media by using prototype methods. The purpose of this research is to analyze the strategy and design of e-marketing websites that are in accordance with the company and can meet customer needs, as a support for marketing media and make it easier for customers to obtain information about existing products. The conclusion is that companies should use the internet as their marketing medium by creating a company website, so that the products and information offered can be easily and quickly obtained by the public.
\end{abstract}

Keywords: E-marketing, e-commeerce, responsive, web design, prototype.

\begin{abstract}
Abstrak
E-marketing merupakan bagian dari e-commerce yang merupakan sistem perdagangan melalui internet, dimana internet akan terus memberikan sifat yang up to date, maka perusahaan dapat memberikan layanan informasi produk yang ditawarkan secara jelas dan mudah. Hal ini akan memberikan dampak yang baik untuk kemajuan perusahaan jika sistem ini bisa dijalankan dengan baik. E-marketing banyak dilakukan untuk meningkatkan brand image perusahaan karena membuat perusahaan selalu diingat oleh pelanggannya. E-marketing banyak memberikan kemudahan dan keuntungan lebih bagi perusahaan, pelanggan dan rekanan bisnis dari perusahaan. Melihat media pemasaran yang masih konvensional, maka dibangun aplikasi design web responsive online sebagai penunjang media pemasaran dengan menggunakan metode prototype. Tujuan dari penelitian ini dibuatkan suatu aplikasi yaitu untuk menganalisis strategi dan desain website e-marketing yang sesuai dengan perusahaan dan dapat memenuhi kebutuhan pelanggan, sebagai penunjang media pemasaran dan mempermudah pelanggan dalam memperoleh informasi mengenai produk-produk yang ada. Kesimpulannya yaitu sebaiknya perusahaan menggunakan internet sebagai media pemasaran mereka dengan cara membuat sebuah website perusahaan, sehingga produk dan informasi yang ditawarkan dapat dengan mudah dan cepat didapatkan oleh masyarakat.
\end{abstract}

Kata Kunci: E-marketing, E-commerce, responsif, desain web, prototipe 


\section{PENDAHULUAN}

Perkembangan teknologi informasi yang pesat turut mempengaruhi dunia bisnis. Arus perputaran informasi di dalam dunia bisnis sangatlah cepat dan bahkan sudah menjadi sebuah kepentingan yang mendesak (Bakri \& Irmayana, 2017; Megawaty, Damayanti, et al., 2021; Muhaqiqin \& Rikendry, 2021), teknologi pun ikut berkembang di dalamnya sehingga menjadi sebuah istilah yang kita kenal dengan teknologi informasi. Salah satu fungsi internet yang menjadi fokus penelitian ini adalah kemampuannya untuk melakukan kegiatan pemasaran baik produk dan brand image secara online bagi siapa saja yang membutuhkan dan terhubung dengan media internet (Alita \& Isnain, 2020; Mindhari et al., 2020; Puspaningrum et al., 2020). Hal ini lah yang disebut dengan e-marketing yang memberikan banyak kemudahan dan keuntungan lebih bagi perusahaan, pelanggan dan rekanan bisnis dari perusahaan (Fitriyana \& Sucipto, 2020; Rosmalasari et al., 2020).

E-marketing sangat menarik karena era globalisasi menuntut banyak kemudahan dan kecepatan informasi. Bagi perusahaan, e-marketing dapat memperluas pasar, memperluas brand image perusahaan, dan memberikan kemudahan dalam memberikan informasi kepada pelanggannya. Sedangkan bagi pelanggan, barang atau jasa yang diinginkan dapat diperoleh tanpa harus meninggalkan rumah atau kantor (mempermudah pelanggan dalam mengakses informasi produk perusahaan), cukup dengan membuka situs web, memilih produk atau jasa yang diinginkan, memesan, melakukan transaksi maka produk atau jasa tersebut akan dikirimkan. Pemilihan strategi $e$ marketing yang cocok dengan perusahaan dan mengetahui detil cara dan dampak penerapannya sangat penting dan diperlukan oleh perusahaan.

Pada umumnya masalah yang dihadapi oleh perusahaan-perusahaan adalah penyebaran informasi hanya terbatas pada para pelanggan tetap sehingga perlu dikembangkan suatu aplikasi pemasaran berbasis web yang dapat memperluas jangkauan pasar dan menarik para pelanggan baru. Kendala-kendala yang ditemukan dalam pemasaran dan pemesanan produk pada perusahaan-perusahaan ini adalah sulitnya mendapatkan informasi yang detail mengenai produk-produk yang dipasarkan dan daerah pemasaran yang kurang luas.

Teknologi informasi berkembang dengan sangat pesat hingga saat ini. Saat ini, jarak dan waktu seakan tidak lagi menjadi halangan dalam berkomunikasi (Setiawan et al., 2021; Sulistiani, Sulistiyawati, et al., 2021). Orang yang berada di pulau yang berbeda bahkan negara yang berbeda kini sudah mampu melakukkan komunikasi bahkan mampu ditampilkan secara visual (Ningsih \& Saniati, 2018; Nugroho et al., 2021). Salah satu hal yang sedang menjadi trend sat ini adalah kegiatan yang berbasis internet dan elektronik (Prastowo et al., 2020).

Tujuan dari penelitian ini yaitu merancang dan membangun sistem informasi yang menyajikan informasi mengenai pemasaran produk makan kerupuk. Merancang desain sistem aplikasi e-marketing berbasis website dalam kegiatan pemasaran produk makanan kerupuk. Menerapkan sistem informasi e-marketing yang dapat dijadikan sebagai media yang dapat diakses melalui komputer maupun gadget.

\section{TELAAH PUSTAKA \\ E-marketing}

E-Marketing adalah membangun dan mempertahankan hubungan dengan pelanggan melalui kegiatan online untuk memfasilitasi pertukaran ide, produk dan pelayanan yang memenihi tujuan kedua belah pihak. Terdapat lima komponen dalam Internet E-Marketing antara lain yaitu proses, membangun dan mempertahankan hubungan dengan pelanggan, pertukaran pemenuhan kepuasan kedua belah pihak. (Rudy, 2010).

Pemasaran adalah suatu proses sosial dan manajerial yang didalamnya individu dan kelompok mendapatkan apa yang mereka butuhkan dan inginkan dengan menciptakan, menawarkan, dan mempertukarkan produk yang bernilai denganpihak lain. (Subing dan Saputra, 2014).

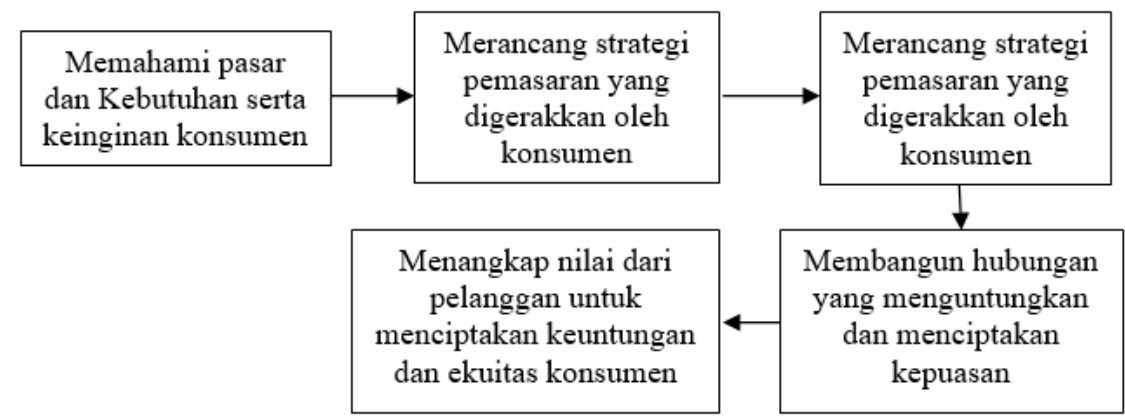

Gambar 1. Model E-Marketing 


\section{METODE PENELITIAN \\ Kerangka Penelitian}

Kerangka penelitian pada dasarnya adalah kerangka hubungan antara konsep konsep yang ingin diamati atau diukur melalui penelitian yang akan dilakukan (Ahdan \& Setiawansyah, 2021; Setiawansyah et al., 2021). Berdasarkan kerangka pemikiran yang ada, maka kerangka penelitian yang digunakan dapat dilihat pada gambar berikut.

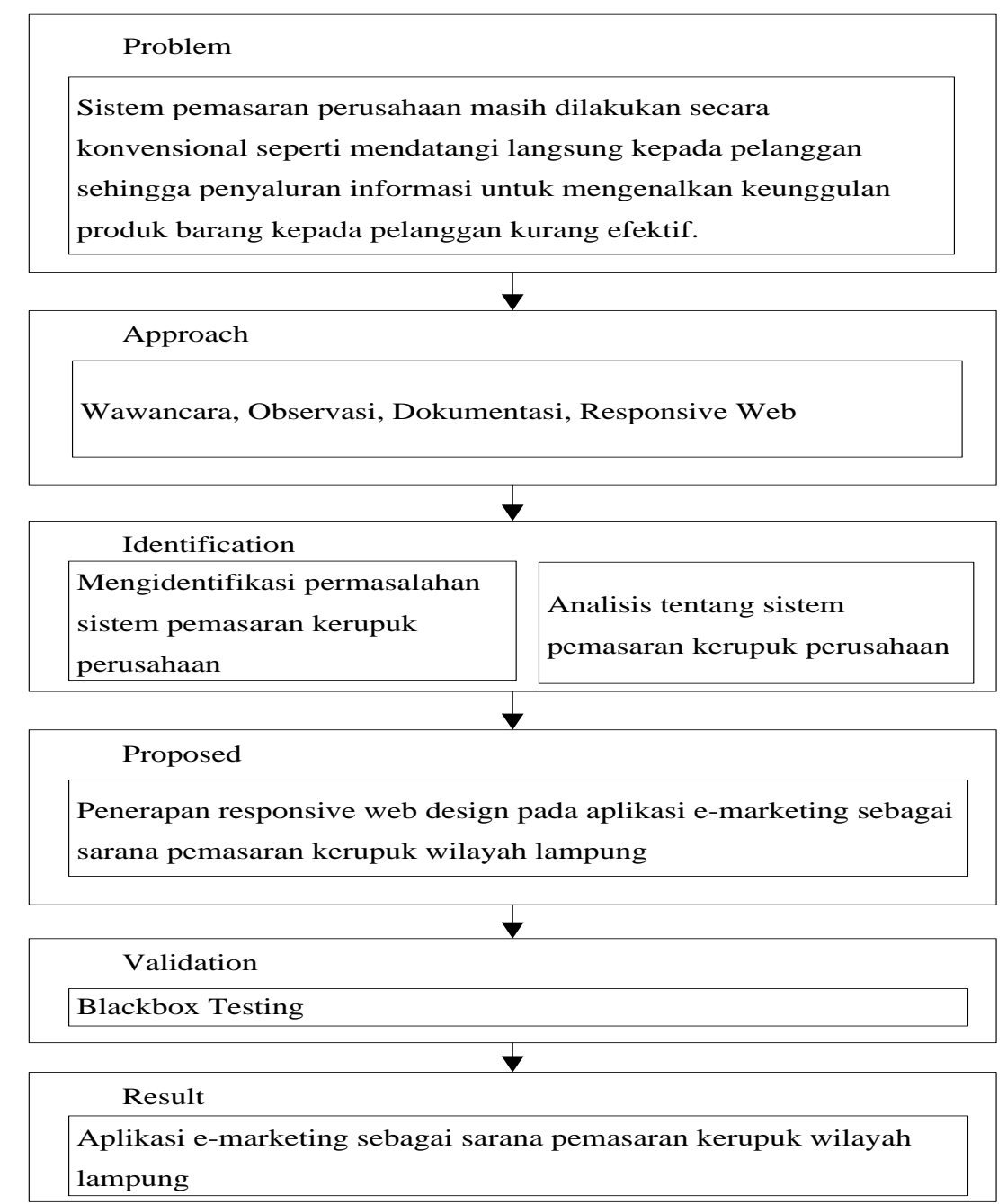

Gambar 2. Kerangka Pemikiran

\section{Metode Analisis Kebutuhan Sistem}

Analisis kebutuhan sistem yang dibutuhkan adalah analisis kebutuhan fungsional (Megawaty, Setiawansyah, et al., 2021; Pasaribu et al., 2019; Sulistiani, Rahmanto, et al., 2021). Usulan pengembangan sistem aplikasi e-marketing sebagai sarana pemasaran kebutuhan pernikahan ini terdiri dari empat diagram yang digambarkan dengan menggunakan perancangan sistem berorientasi objek.

\section{Use Case Diagram}

Use case atau diagram use case merupakan pemodelan untuk kelakuan (behavior) sistem promosi yang akan dibuat. 


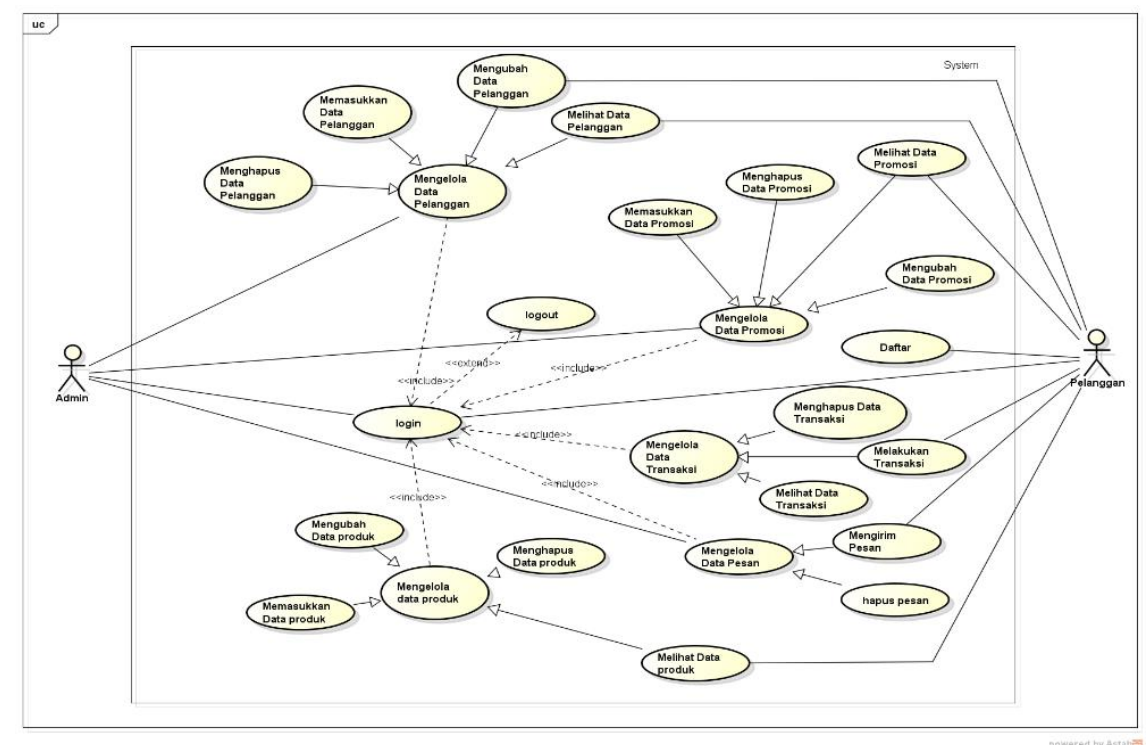

Gambar 3. Use Case Diagram

\section{Class Diagram}

Class diagram menggambarkan struktur sistem dari segi pendefinisian kelas-kelas yang akan dibuat untuk membangun sistem (Sulistiani, Yuliani, et al., 2021). Terdapat beberapa class pada class diagram yang terdapat pada gambar 4 yaitu class main yang berfungsi sebagai kelas main itu sendiri, kelas antarmuka yang menangani tampilan, login sistem untuk pendefinisian use case login, begitu juga dengan mengelola pelanggan, mengelola produk, mengelola transaksi, mengelola promosi dan mengelola pesan.

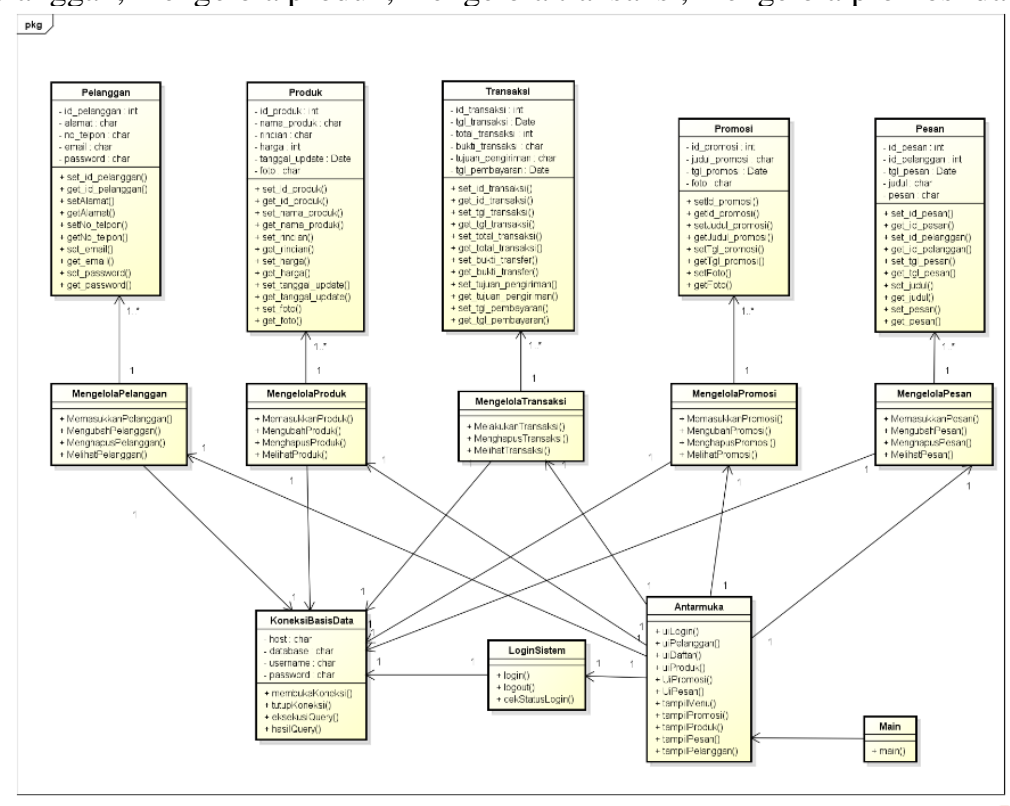

Gambar 4. Class Diagram

\section{HASIL DAN PEMBAHASAN}

Setelah melakukan penelitian, analisa, perancangan dan pembuatan aplikasi yang sudah jadi akan di implemetasi-kan pada sejumlah penjualan kerupuk yang ingin melakukan promosi pada penjualan kerupuk di PT ASIA CRACKER JAYA untuk menguji layak atau tidaknya sistem. Selain dengan implementasi langsung terdapat 
juga pengujian black box. Kemudian melakukan pelatihan terhadap pelanggan yang akan menggunakan aplikasi dan pengetahuan yang cukup tentang penggunaan aplikasi yang dibuat, agar pelanggan memahami cara pengggunaan aplikasi tersebut (Mahmuda et al., 2021), serta dapat mengurangi kesalahan yang akan timbul, sehingga tujuan pembangunan sistem mempermuda pelanggan untuk memesan barang yang tersedia

\section{Dashboard Aplikasi}

Menu utama merupakan tampilan utama dalam sistem aplikasi, menu utama ini berfungsi untuk memudahkan pelanggan dalam mencari daftar produk yang ada didalam sistem, dan dapat mencari produk yang sesuai dengan harga yang dimiliki, agar pelanggan tertarik untuk membeli, berikut gambar tampilan menu utama sistem penjualan kerupuk
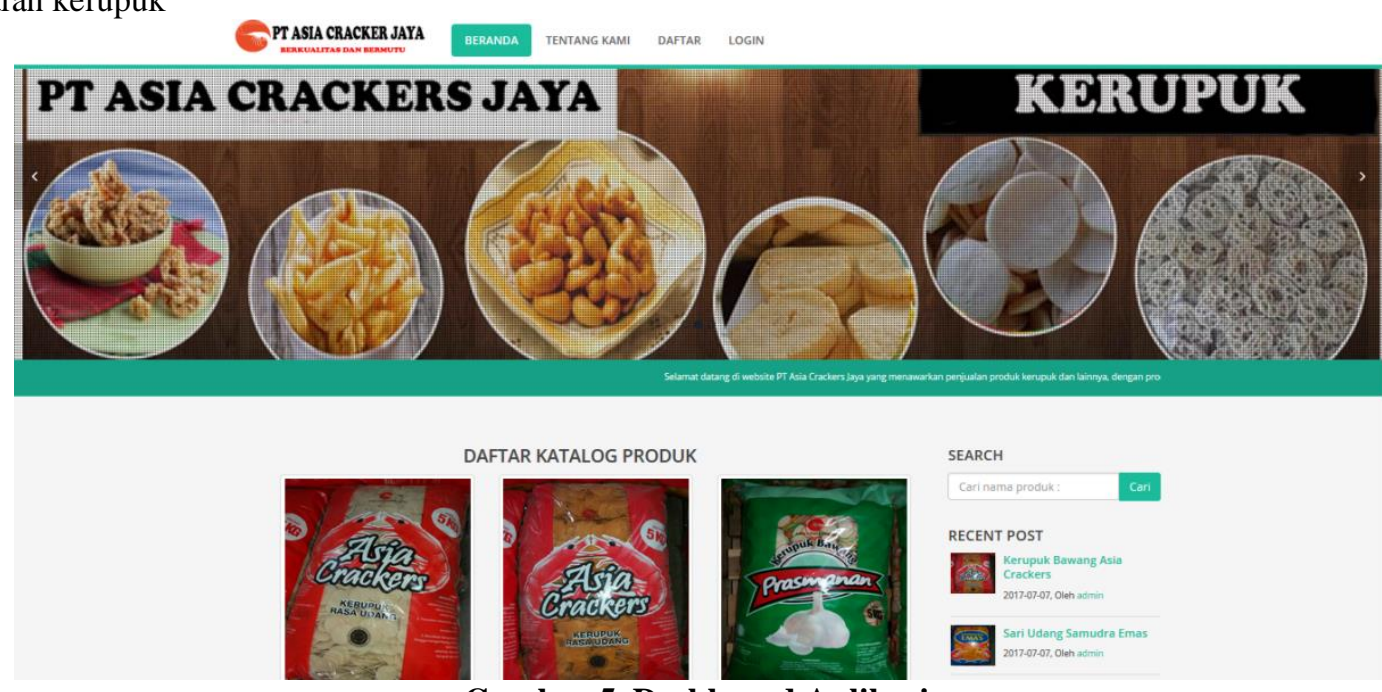

Gambar 5. Dashboard Aplikasi

\section{Halaman Daftar Pelanggan}

Tampilan form daftar pelanggan merupakan tampilan pada saat pelanggan megklik menu daftar, tampilan form ini berfungsi sebagai form pendaftaran pelanggan agar pelanggan dapat menggunakan sistem, dan memiliki akun untuk login kedalam sistem dan melakukan service.

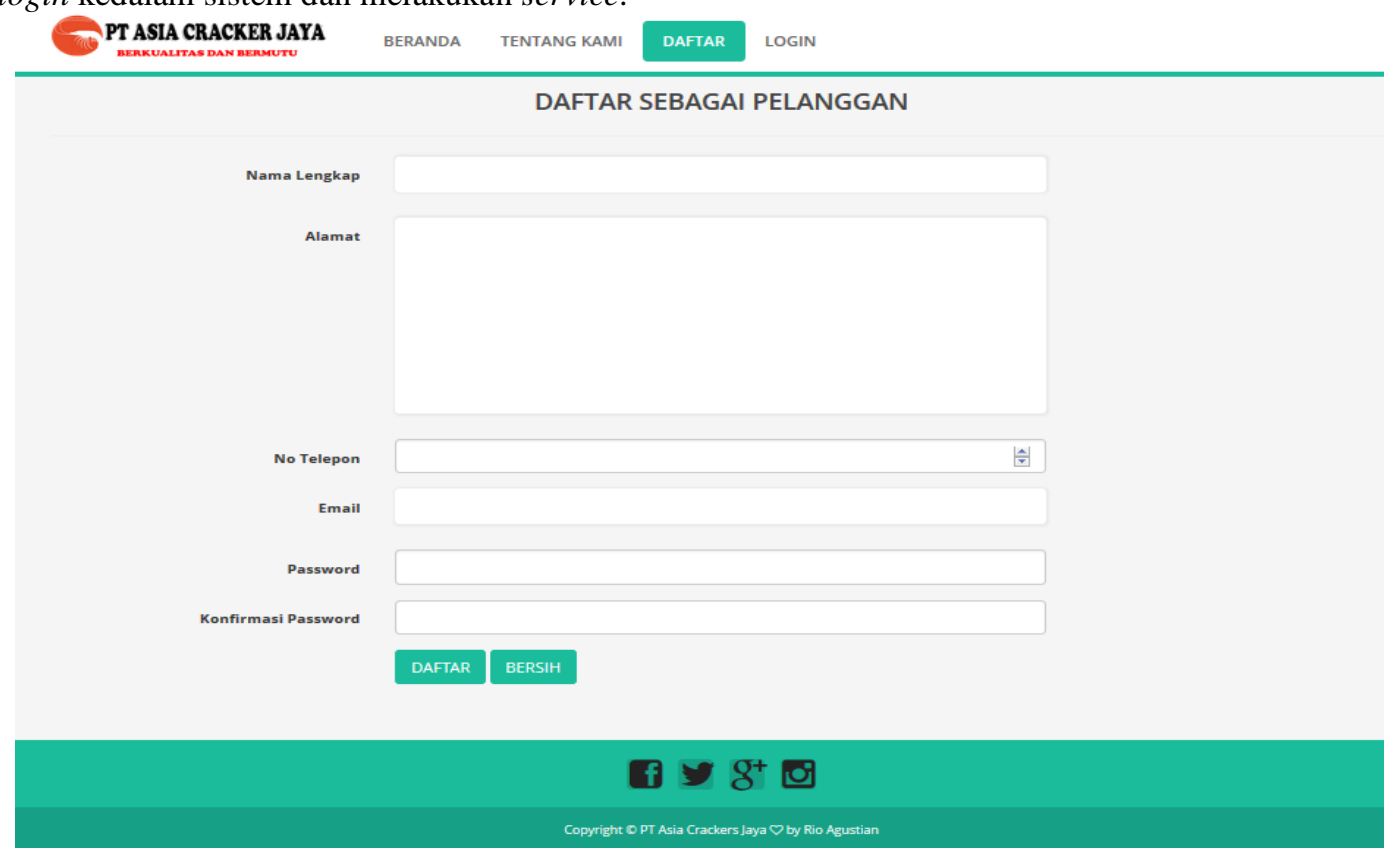

Gambar 6. Halaman Daftar Pelanggan 


\section{Halaman Keranjang Belanja}

Tampilan form keranjang belanja ini berfungsi untuk melakukan melihat hasil pemesan produk yang sudah di pilih oleh pelanggan. Sebelum melihat hasil pemesanan pelanggan, pelanggan harus login terlebih dahulu jika ingin menggunakan sistem aplikasi yang ada

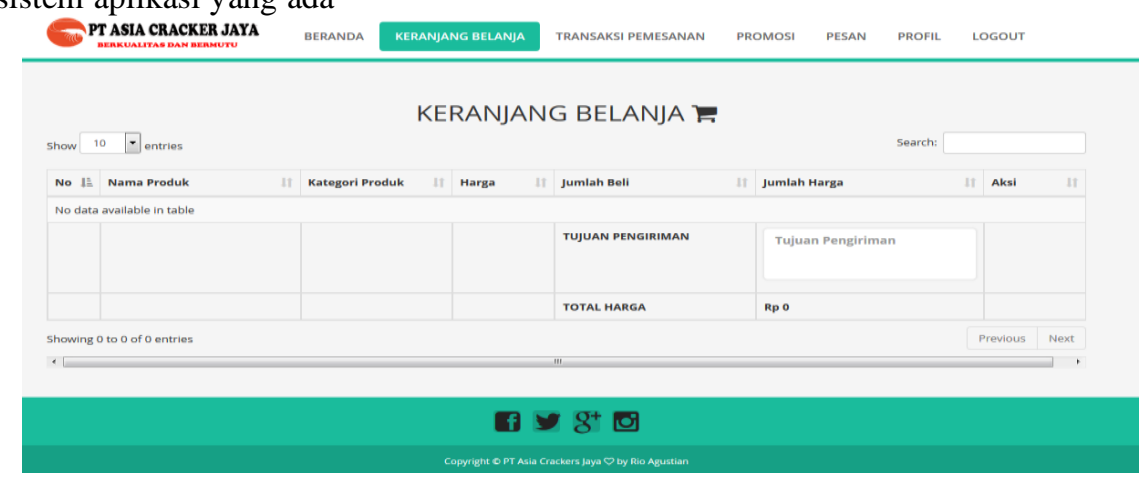

Gambar 7. Halaman Keranjang Belanja

\section{Halaman Pemesanan}

Tampilan form transaksi pemesanan ini berfungsi untuk melakukan melihat hasil pemesan produk yang sudah di pilih pesan pelanggan. Sebelum melihat hasil pemesanan pelanggan, pelanggan harus login terlebih dahulu jika ingin menggunakan sistem aplikasi yang ada

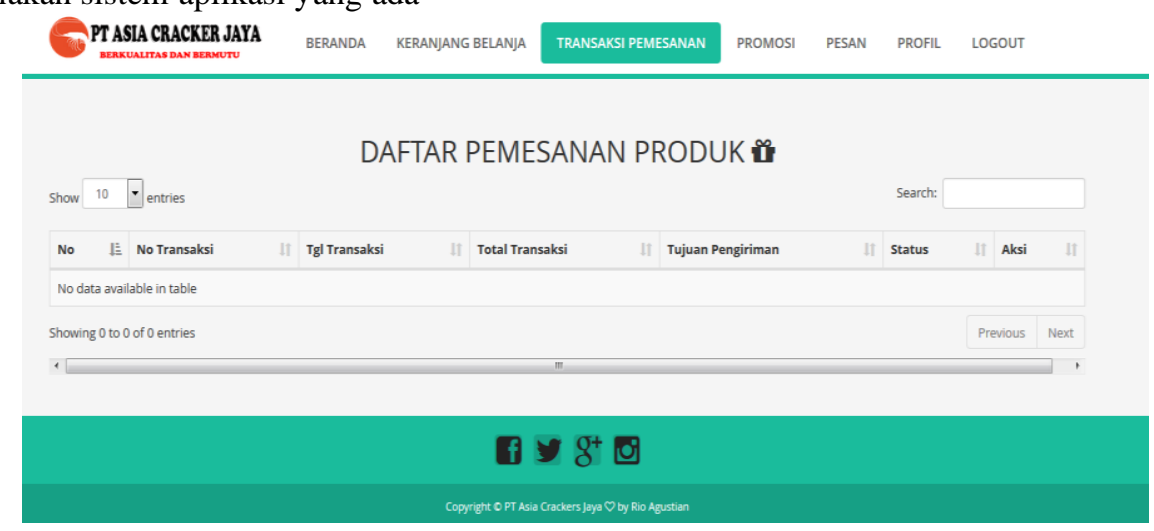

Gambar 8. Halaman Pemesanan

\section{Halaman Promosi}

Tampilan form promosi ini berfungsi untuk melakukan melihat daftar produk promosi yang sudah di ada. Sebelum melihat hasil daftar produk promosi, pelanggan harus login terlebih dahulu jika ingin menggunakan sistem aplikasi yang ada

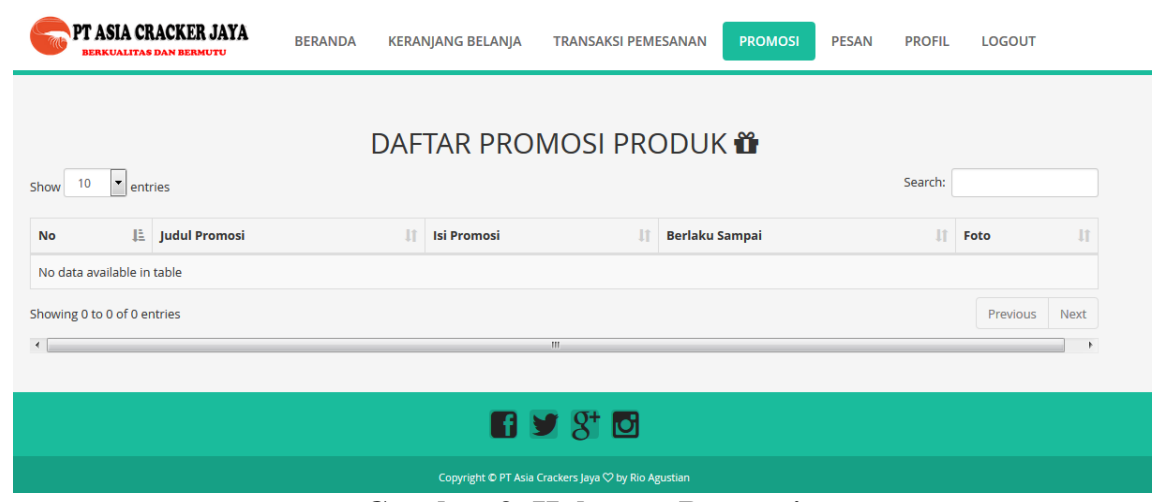

Gambar 9. Halaman Promosi 


\section{SIMPULAN}

Berdasarkan hasil pembahasan dapat diambil kesimpulan yaitu Dengan adanya sistem aplikasi ini pencarian informasi kerupuk pada PT Asia Crackers Jaya dapat dicari dengan menggunakan gadget seperti smartphone, tablet, dan lain-lain sehingga memudah kan pelanggan dalam mencari kerupuk yang dibutuhkan. Dengan adanya sistem aplikasi ini pelanggan dapat melakukan pemesanan kerupuk secara online sesuai dengan kebutuhan. Berdasarkan pengujian penerapan responsive web design pada aplikasi e-marketing sebagai sarana pemasaran kebutuhan pernikahan pada wilayah bandar lampung dapat diimplementasikan.

\section{REFERENSI/DAFTAR PUSTAKA}

Ahdan, S., \& Setiawansyah, S. (2021). Android-Based Geolocation Technology on a Blood Donation System (BDS) Using the Dijkstra Algorithm. IJAIT (International Journal of Applied Information Technology), 1-15.

Alita, D., \& Isnain, A. R. (2020). Pendeteksian Sarkasme pada Proses Analisis Sentimen Menggunakan Random Forest Classifier. Jurnal Komputasi, 8(2), 50-58.

Bakri, M., \& Irmayana, N. (2017). Analisis Dan Penerapan Sistem Manajemen Keamanan Informasi SIMHP BPKP Menggunakan Standar ISO 27001. Jurnal Tekno Kompak, 11(2), 41-44.

Fitriyana, F., \& Sucipto, A. (2020). SISTEM INFORMASI PENJUALAN OLEH SALES MARKETING PADA PT ERLANGGA MAHAMERU. Jurnal Teknologi Dan Sistem Informasi, 1(1), 105-110.

Mahmuda, S., Sucipto, A., \& Setiawansyah, S. (2021). Pengembangan Sistem Informasi Pengolahan Data Tunjangan Karyawan Bulog (TKB)(Studi Kasus: Perum Bulog Divisi Regional Lampung). Jurnal Ilmiah Sistem Informasi Akuntansi, 1(1), 14-23.

Megawaty, D. A., Damayanti, D., Assubhi, Z. S., \& Assuja, M. A. (2021). APLIKASI PERMAINAN SEB AGAI MEDIA PEMBELAJARAN PETA DAN BUDAYA SUMATERA UNTUK SISWA SEKOLAH DASAR. Jurnal Komputasi, 9(1), 58-66.

Megawaty, D. A., Setiawansyah, S., Alita, D., \& Dewi, P. S. (2021). Teknologi dalam pengelolaan administrasi keuangan komite sekolah untuk meningkatkan transparansi keuangan. Riau Journal of Empowerment, 4(2), 95-104.

Mindhari, A., Yasin, I., \& Isnaini, F. (2020). PERANCANGAN PENGENDALIAN INTERNAL ARUS KAS KECIL MENGGUNAKAN METODE IMPREST (STUDI KASUS: PT ES HUPINDO). Jurnal Teknologi Dan Sistem Informasi, 1(2), 58-63.

Muhaqiqin, M., \& Rikendry, R. (2021). ALT+ F: APLIKASI PENCARIAN LAWAN TANDING FUTSAL BERBASIS MOBILE ANDROID. J-Icon: Jurnal Komputer Dan Informatika, 9(1), 81-87.

Ningsih, S., \& Saniati, S. (2018). Eksperimen Pengenalan Ucapan Aksara Lampung Dengan CMU Sphinx 4. Jurnal Teknoinfo, 12(1), 33-37.

Nugroho, N., Napianto, R., Ahmad, I., \& Saputra, W. A. (2021). PENGEMB ANGAN APLIKASI PENCARIAN GURU PRIVAT EDITING VIDEO BERBASIS ANDROID. Jurnal Informasi Dan Komputer, 9(1), 72-78.

Pasaribu, A. F. O., Darwis, D., Irawan, A., \& Surahman, A. (2019). Sistem Informasi Geografis untuk Pencarian Lokasi Bengkel Mobil di Wilayah Kota Bandar Lampung. Jurnal Tekno Kompak, 13(2), 1-6.

Prastowo, A. T., Darwis, D., \& Pamungkas, N. B. (2020). Aplikasi Web Pemetaan Wilayah Kelayakan Tanam Jagung Berdasarkan Hasil Panen Di Kabupaten Lampung Selatan. Jurnal Komputasi, 8(1), 21-29.

Puspaningrum, A. S., Neneng, N., Saputri, I., \& Ariany, F. (2020). PENGEMBANGAN E-RAPORT KURIKULUM 2013 BERBASIS WEB PADA SMA TUNAS MEKAR INDONESIA. Jurnal Komputasi, 8(2), 94-101.

Rosmalasari, T. D., Lestari, M. A., Dewantoro, F., \& Russel, E. (2020). Pengembangan E-Marketing Sebagai Sistem Informasi Layanan Pelanggan Pada Mega Florist Bandar Lampung. Journal of Social Sciences and Technology for Community Service (JSSTCS), 1(1), 27-32.

Setiawan, M. B., Susanto, T., \& Jayadi, A. (2021). PENERAPAN SISTEM KENDALI PID PESAWAT TERB ANG TANPA AWAK UNTUK KESETABILAN ROLL, PITCH DAN YAW PADA FIXED WINGS. The 1st International Conference on Advanced Information Technology and Communication (IC-AITC).

Setiawansyah, S., Adrian, Q. J., \& Devija, R. N. (2021). Penerapan Sistem Informasi Administrasi Perpustakaan Menggunakan Model Desain User Experience. Jurnal Manajemen Informatika (JAMIKA), 11(1), 24-36.

Sulistiani, H., Rahmanto, Y., Putra, A. D., \& Fahrizqi, E. B. (2021). PENERAPAN SISTEM PEMBELAJARAN DALAM JARINGAN UNTUK MENINGKATKAN KUALITAS BELAJAR DALAM MENGHASILKAN SISWA 4.0. Journal of Social Sciences and Technology for Community Service (JSSTCS), 2(2), 178-183.

Sulistiani, H., Sulistiyawati, A., \& Hajizah, A. (2021). Perancangan Sistem Pengelolaan Keuangan Komite Menggunakan Web Engineering (Studi Kasus: SMK Negeri 1 Gedong Tataan). Komputika: Jurnal Sistem Komputer, 10(2), 163-171.

Sulistiani, H., Yuliani, A., \& Hamidy, F. (2021). Perancangan Sistem Informasi Akuntansi Upah Lembur Karyawan Menggunakan Extreme Programming. Technomedia Journal, 6(01 Agustus). 